\title{
Review
}

\section{The Middle Latency Response: A Review of Findings in Various Central Nervous System Lesions}

DOI: $10.3766 /$ jaaa.16141

Frank Musiek*

Stephanie Nagle $\dagger$

\begin{abstract}
Background: The middle latency response (MLR) first came to light as an auditory evoked potential in 1958. Since then, it has aroused substantial interest and investigation by clinicians and researchers alike. In recent history, its use and popularity have dwindled in tandem with various other auditory evoked potentials in audiology. One area for which MLR research and application has been overlooked is its potential value in measuring the neural integrity of the auditory thalamocortical pathway. In a broader sense, the MLR, when combined with the auditory brain stem response, can provide information concerning the status of much of the central auditory system pathways. This review is intended to provide information concerning the MLR as a measure of central auditory function for the reader to consider.
\end{abstract}

Purpose: To review and synthesize the scientific literature regarding the potential value of the MLR in assessing the integrity of the central auditory system and to provide the reader an informed perspective on the value of the MLR in this regard. Information is also provided on the MLR generator sites and fundamental characteristics of this evoked potential essential to its clinical and or research application.

Research Design: A systematic review and synthesis of the literature focusing on the MLR and lesions of the central auditory system.

Study Sample: Studies and individual cases were reviewed and analyzed that evidenced documented lesions of the central auditory nervous system.

Data Collection and Analysis: The authors searched and reviewed the literature (journal articles, book chapters, and books) pertaining to central auditory system lesion effects on the MLR.

Results: Although findings varied from study to study, overall, the MLR was reasonably sensitive and specific to neurological compromise of the central auditory system. This finding is consistent with the generator sites of this evoked potential.

Conclusions: The MLR is a valuable tool for assessing the integrity of the central auditory system. It should be of interest to the clinician or researcher who focuses their attention on the function and dysfunction of the higher auditory system.

Key Words: auditory evoked potentials, central auditory nervous system, lesion, middle latency response

Abbreviations: $\mathrm{ABR}=$ auditory brain stem response; CANS = central auditory nervous system; $\mathrm{MGB}=$ medial geniculate body; MLR = middle latency evoked response

*The University of Arizona, Tucson, AZ; †Connecticut Children's Medical Center, Hartford, CT

Corresponding author: Frank Musiek, The University of Arizona, Tucson, AZ 85719; Email: fmusiek@email.arizona.edu. 


\section{INTRODUCTION}

$\mathrm{T}$ he middle latency evoked response (MLR), also termed the auditory middle latency response, has been somewhat of a maligned evoked potential in many ways. One aspect of the MLR that has not received its due is its possible value in reflecting the functional integrity of the central auditory nervous system (CANS). Therefore, the purpose of this article is to review the MLR findings in CANS disorders.

By way of overview, the MLR follows the auditory brain stem response (ABR) in time and consists of a negative wave $\mathrm{Na}(\sim 15-22 \mathrm{msec})$, a first positive wave $\mathrm{Pa}$ $(\sim 24-34 \mathrm{msec})$, a second negative wave $\mathrm{Nb}(\sim 35-50$ msec), and a second positive wave $\mathrm{Pb}(\sim 50-60 \mathrm{msec})$ (see Musiek and Lee, 1999; Hall, 2007 for reviews). Amplitude of the MLR, specifically the $\mathrm{Na}-\mathrm{Pa}$ wave, is larger than the $\mathrm{ABR}$ and often averages about $1 \mu \mathrm{V}$ at moderate intensities (see Musiek and Lee, 1999; Pratt, 2007). Both latency and amplitude are variable depending on the type of stimulus, its intensity, filtering, and a host of other factors (see Musiek and Lee, 1999; Hall, 2007; Pratt, 2007; Picton, 2011 for reviews) As discussed later, the generators of the MLR are structures along the thalamocortical pathway, although some disagreement as to specific sites exists. These MLR generators are rostral to the ABR generator sites; this allows the MLR to provide insight as to function in an additional region of the higher auditory system.

In this review, the focus is on MLR findings in lesions of the CANS, but some preliminary comments about this topic are warranted. In the MLR, the amplitude measures seem to be more sensitive than latency measures. This is especially the case when there are asymmetries that are revealed by electrode responses over the two hemispheres. This depicts an intra-subject comparison, which is perhaps a more sensitive measure than inter-subject comparisons, although both have shown reasonable results. In some cases of neuroauditory involvement, the MLR is absent (unilaterally or bilaterally), which strongly suggests central auditory dysfunction. Asymmetrical recordings when one side reveals no response is an easy interpretation, but varying degrees of asymmetry are more difficult to interpret. Deciding how much reduction constitutes "asymmetry" depends on many recording factors such as the kind of averager, stimuli used, electrode loci, participant age, and recording characteristics. These factors need to be highly similar across labs and clinics to allow universal normative and diagnostic data.

\section{MLR GENERAL CHARACTERISTICS}

\section{Waveform}

The MLR occurs approximately 12-75 msec after stimulus onset. It is composed of two positive and two negative components: $\mathrm{Na}$, which typically occurs between 12 and $21 \mathrm{msec} ; \mathrm{Pa}$, which typically occurs between 21 and $38 \mathrm{msec}$;

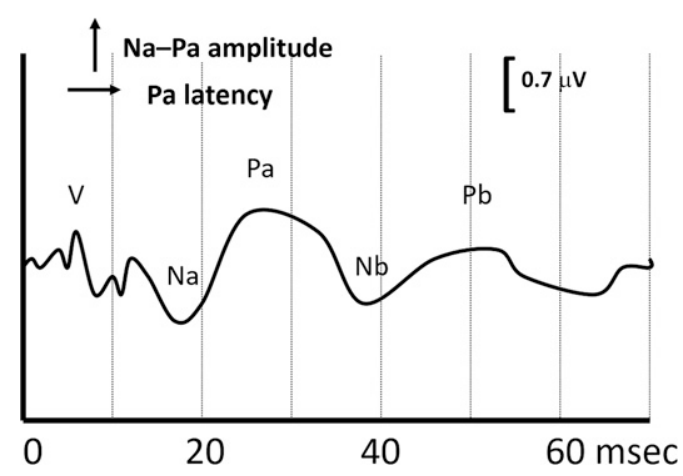

Figure 1. A depiction of a normal MLR waveform showing the various waves and an example of latency and amplitude measures.

$\mathrm{Nb}$, which typically occurs just after $\mathrm{Pa}$; and $\mathrm{Pb}$, which occurs after $\mathrm{Nb}$, at approximately $50 \mathrm{msec}$ (Musiek et al, 1999; Pratt, 2007) (see Figure 1 for a sample MLR waveform). Typically, only the early components of the MLR, Na and $\mathrm{Pa}$, are used clinically for presence/absence judgments and amplitude and latency analysis as the $\mathrm{Pb}$ wave is not reliably evoked by typical clinical MLR paradigms (Özdamar and Kraus, 1983; Erwin and Buchwald, 1986; Nelson et al, 1997). Also, if the MLR is administered at equal sensation levels above threshold, there is little effect of hearing loss on the MLR waveform (McFarland et al, 1977).

The MLR can be recorded in both children and adults with appropriate rate and filter settings, but the waveform undergoes changes in morphology, latency, and amplitude correlated with the maturation of the central nervous system (Hall, 2007). In infants and young children, Pa may occur later and have smaller amplitude as well as a broader peak (Fifer and Sierra-Irizarry, 1988; Hall, 2007). As children age, $\mathrm{Pa}$ amplitude increases steadily, with the MLR becoming adult-like at 8-10 years of age (Hall, 2007; Pratt, 2007). The Pb component, in contrast, matures more slowly, reaching adult values at approximately 15 years of age (Ponton et al, 1996). Maturation of this component has been shown to be delayed in individuals with auditory deprivation due to hearing loss (Ponton et al, 1996).

It has also been reported that MLR amplitude may be affected according to ipsilateral or contralateral recording of the response. Seki et al (1993) found that the amplitudes of waves $\mathrm{Na}$ and $\mathrm{Pa}$ in humans tend to be slightly larger at the electrode contralateral to the stimulus. Tucker and Ruth (1996) also showed results that corroborated Seki et al's findings. These researchers observed that the ipsilateral response was present for all participants, whereas the presence of the contralateral MLR was recorded in adults $70-100 \%$ of the time.

\section{Abnormal Responses}

\section{Ear and Electrode Effects}

The concept and terminology of ear and electrode effects have been discussed for some time. Peronnet and 
Michel (1977), Scherg and Von Cramon (1986), and Musiek and Lee (1999) were among the first to describe the electrode effect but all did not use that specific terminology. These effects are predicated on placing $\geq 1$ electrode over C3, C5, or T3 of the left hemisphere and $\mathrm{C} 4, \mathrm{C} 6$, or $\mathrm{T} 4$ at the right hemisphere. It is also preferable to have an electrode at midline $(\mathrm{Cz})$. The concept behind the electrode effect is that the electrode closest to the lesion site yields the smallest amplitude or the greatest latency when compared with other electrode sites. The ear effect occurs when regardless of electrode site, stimulation of one ear yields a smaller amplitude and a longer latency than responses obtained by stimulating the other ear. The ear effect does not necessarily provide information as to lesion site in the same way that the electrode effect does. The ear effect does not seem to be a strong indicator of which hemisphere the lesion is located-it could be contralateral or ipsilateral (Musiek et al, 1999).

As alluded to earlier, intra-subject measures such as electrode and ear effects are more appealing because of the variability of inter-subject measures of amplitude and to a lesser degree latencies. However, there are studies that have clearly demonstrated that inter-subject measures for the MLR can be sensitive (Musiek and Lee, 1997; Japaridze et al, 2002). These studies will be discussed in further depth in the following paragraphs.

Clearly, there is empirical evidence to show diagnostic value of the MLR in comparing groups with lesions of thalamocortical areas to controls. However, establishing universal norms (especially for amplitude) has been difficult for a number of reasons as alluded to earlier. The variability of the MLR across studies may be, in part, related to differences in filtering, stimuli used, types of averagers, repetition rate, and specific electrode placement. These factors, in addition to the natural variability of the MLR, create a challenge. Nonetheless, normative criteria have been offered based on decision matrix analyses and clinical experience (Ibañez et al, 1989; Musiek et al, 1999). Large amplitude differences in MLR recordings comparing electrode sites (usually left versus right hemisphere sites) is a good indicator of dysfunction of the side with the poorer response (Kraus et al, 1982; Scherg and Von Cramon, 1986; Kileny et al, 1987; Ibeñez et al, 1989; Musiek et al, 1999). However, to establish universal norms, the nonpathologic factors mentioned (rate, filtering, etc.) would likely also have to be universal. A consistently absent MLR combined with a normal or near normal ABR, good hearing sensitivity, and a suggestive history can be a strong indicator of central auditory involvement (Musiek and Lee, 1999).

\section{Recording Parameters}

\section{Stimuli}

The MLR can be obtained using either clicks or tonal stimuli. In regard to neuroaudiological applications, clicks are generally used. However, there are some situations where tones may be the stimulus of choice. For example, if the patient has high-frequency hearing loss and normal hearing in the low frequencies, a low-frequency stimulus may be used in an attempt to mitigate the effects of hearing loss.

The presentation rate commonly used with adults is often approximately ten stimuli per second. In newborns, the presentation rate can influence the response with slower rates (1-2 per second), yielding a greater presence of waveforms than higher rates ( $\sim 10$ per second) (Jerger et al, 1987). Extremely high rates of presentation using techniques such as maximum length sequences have been used in adults and have yielded smaller but well-formed waveforms (Musiek and Lee, 1997; Nagle and Musiek, 2009).

\section{Trials}

The number of trials for the MLR can vary but is commonly $\sim 1,000$ trials/averages per waveform. When the $\mathrm{ABR}$ and MLR are recorded together, a greater number of trials $(\sim 1,500)$ may be used (see Hall, 2007 for more discussion). When available, Fsp applications can be used to help determine the best response instead of using a prescribed number of trials. As with any evoked potential, all waveforms should be replicated to ensure that they represent a true neural response.

\section{Electrodes}

In neuroaudiological applications, electrode(s) should be placed over each hemisphere. This allows the determination of ear and electrode effects, which can help in localization of the lesion (see Kileny et al, 1987; Musiek and Lee, 1999). Generally, the lateral electrode is placed at C3, T3, or C5 over the left hemisphere and C4, T4, or C6 over the right hemisphere (see Kileny et al, 1987; Musiek and Lee, 1999). MLRs recorded from these sites in neurologically intact individuals are usually quite similar in amplitude and latency (Jacobson and Grayson, 1988). The Cz electrode site generally provides the largest response and should be used with electrodes placed at the lateral sites just mentioned. The reference electrode can be clipped to the earlobe of the ear that is acoustically stimulated. A midline site such as the nape of the neck or mid chin is considered a nonbiased site which can be useful in determining laterality effects (Jacobson and Grayson, 1988). The election of electrode sites of those mentioned here may depend on the array used for the collection of normative data for a particular averager. That is, although C3, C4, C5, C6, T3, and T4 are similar in terms of the response obtained, waveforms obtained from these sites may be slightly different. If normative data (or other data) are acquired from a particular site, then that site should be used for normed comparisons or for replicating studies. As with most evoked potential recordings, impedance at the electrodes sites should be $<5,000 \Omega$ with minimal differences across electrodes. 


\section{Filtering}

In neuroaudiological applications, the MLR filter band can range from 5 to $30 \mathrm{~Hz}$ for the high band pass and 1500 $\mathrm{Hz}$ for the low band pass with roll-offs in the 6-12 $\mathrm{dB}$ per octave range (Suzuki et al, 1984; Musiek and Lee, 1999). These values are for analog filters, which are common for many commercial instruments. Narrower filter bands can be used and are achieved by reducing the low band pass (i.e., 20-200 Hz). This would make the waveform smoother and morphology clearer, but then the ABR becomes difficult to observe. For simultaneous recording of the $\mathrm{ABR}$ and MLR, filters of 20 or 30-1500 Hz are recommended (Suzuki et al, 1984; Musiek, 1991). Also in analog instruments, phase shifting and or ringing can occur with narrower filter bands (especially if the filter roll-offs are sharp).

\section{Generator Sites}

Most researchers agree that the auditory middle latency response is generated from anatomical sites between the inferior colliculus and the auditory cortex, and many further believe that this response occurs somewhere along the thalamocortical pathway (Baess et al, 2009). The basis for this likely lies in animal research from McGee et al (1991). McGee showed temporal components A, B, and C (with wave A as a positive component occurring at $12 \mathrm{msec}$, wave $\mathrm{B}$ as a negative component at $21 \mathrm{msec}$, and wave $\mathrm{C}$ as a positive component at $33 \mathrm{msec}$ ) originating in the thalamocortical pathway in the guinea pig. Claiming the MLR is a thalamocortical response infers that the inferior colliculus may not contribute to the MLR because it is a midbrain structure.

\section{Inferior Colliculus}

Although most agree that the MLR is generated from this general area, there are some differences as to what particular areas along this pathway actually generate the components of the MLR. Hashimoto (1982) and McGee et al (1991) claim that the inferior colliculus plays a role in the generation of the MLR. More specifically, these researchers claim that in human wave $\mathrm{Na}$ and in guinea pig wave $\mathrm{M}-$ (first negative wave) originate from this midbrain structure.

\section{Thalamus}

The next probable generator site of the MLR is the thalamus. Previous research has shown that the thalamus may be responsible for the generation of components of the MLR (Kraus et al, 1988; Knight and Brailowsky, 1990). Stating that the thalamus plays a role in the generation of the MLR is a very general statement, and it is likely used to avoid specificity that is beyond what the anatomical data show. This may be prudent and is done because the auditory functions of the thalamic nuclei are not very well understood. The thalamus itself contains nuclei for many different func- tions; therefore, it is the assumption of the present authors that the specific areas being referred to include the medial geniculate body (MGB), reticular nucleus, and possibly the pulvinar (see McGee et al, 1991; Musiek and Baran, 2007). McGee et al (1992) suggest that different subdivisions (dorsal, medial, and ventral) of the MGB in humans contribute differently to the MLR and that the temporal response is associated with the primary auditory pathway; so the ventral nucleus of the MGB is likely most involved. The primary, or classical, auditory pathway includes only the anatomical structures involved in processing auditory information, whereas the nonclassical auditory pathway also receives inputs from many other systems, including the amygdala, the dorsal nuclei of the thalamus, the dorsal column nuclei, and the median nerve. It diffuses more than the classic pathway, and it is thought to course through the external nucleus of the inferior colliculus to the reticular formation to the medial and dorsal geniculate and on to the association cortices (Musiek et al, 2011). Because of its location, it could play a role in the MLR. It is clear that the nonclassical auditory pathway exists, but there is still some uncertainty in terms of its actual functions and neural connections (Møller et al, 1992; 2005). Although many agree that the thalamus is an important part of the pathway that gives rise to the MLR, few authors have investigated the specific components to which the thalamus contributes. Most consider the early waves to be generated by the more caudal structures and the later waves more rostral in the pathway (Kraus and Nicol, 2009). Based on their work with cats, Kaga et al (1980) claim that MLR wave Pa originates at the MGB of the thalamus. However, Kraus et al (1988) found that in gerbils and albino guinea pigs, the thalamus contributes to the midline MLR responses (MLR waves are stronger at the midline position of the electrode). In another study done by Hinman and Buchwald (1983), the authors claimed that the thalamus give rise to the MLR vertex wave A (positive wave occurring 17-25 msec poststimulus onset) in cats.

Another anatomical area that Kraus et al (1988; 1992), and McGee et al (1991) associated with the generation of the MLR is the reticular nucleus. Their work with guinea pigs has shown that the reticular nucleus may play a role in generating the MLR midline response and is involved in attention and responsiveness to acoustic stimulation (Musiek and Baran, 2007). If the reticular nucleus is involved in generating the MLR, it is unclear whether the MLR occurs in response to the stimulus itself or because of the patient's attention to the stimulus. Attention contributes to the waveform, likely in a minor way. MLR waves have reduced amplitude when participants do not attend to the stimulus (Eisencraft et al, 2006).

\section{Auditory Cortex}

Most researchers agree that the auditory cortex is a primary generator of the MLR. However, the specific 
areas of the auditory cortex which give rise to different waves of the MLR are variable in the literature. Based on their work with cats, Kaga et al (1980) as well as Knight and Brailowsky (1990) concur that at least wave $\mathrm{Pa}$ of the MLR arises from the auditory cortex. Knight and Brailowsky (1990) affirmed that wave Nb likely arises from the auditory cortex as well. Kraus et al (1988) found that MLR responses recorded over the temporal lobe in guinea pigs are most likely generated by the auditory cortex. Using superconducting quantum interference device technology with normal human participants, Makela et al (1994) and Yoshiura et al (1995) found that waves $\mathrm{Na}, \mathrm{Pa}, \mathrm{Nb}$, and $\mathrm{Pb}$ were all generated within the auditory cortex. Other researchers, such as Kuriki et al (1995), have narrowed the location of the responses down to Heschl's gyrus using magnetoencephalography. Yvert et al (2001) used magnetoencephalography and electroencephalography measurements to locate the MLR responses in Heschl's sulcus and along the supratemporal gyrus. Liegeois-Chauvel et al (1994) used stereoelectroencephalographic exploration with chronic intracerebral electrodes in their study, and they were able to pinpoint different components of the MLR responses to specific areas of the temporal lobe. These researchers found that in humans, wave $\mathrm{N} 30(\mathrm{~Pa})$ is generated in the medial portion of the primary auditory cortex, whereas $\mathrm{P} 50(\mathrm{Nb})$ arises from the lateral section. They also found that waves $\mathrm{N} 60$ and $\mathrm{N} 75$ (Pb and $\mathrm{P} 1$, respectively) are generated from the secondary auditory cortex.

In summary, although there are some modestly differing views, it appears that the MLR waves are essentially generated from thalamic auditory structures and the auditory cortex. It seems possible that the inferior colliculus may contribute to $\mathrm{Na}$ and that perhaps the reticular nucleus contributes to the overall waveform; however, final determination of the contributions to the MLR of these neural generators awaits more investigation.

\section{LESION STUDIES}

A large body of research has documented the effects of various types of lesions to the central nervous system on the MLR. Overall, the MLR has been more widely studied in cases of cortical involvement, with the effects of brain stem and subcortical insult or injury less well documented. Published studies range from large-scale comparisons with control groups to small sample sizes or individual case studies. Sensitivity values have been calculated for the larger studies and are included in parentheses where possible.

\section{Brain Stem, Thalamic, and Subcortical Involvement}

The largest brain stem study to date was performed in France by Henry-Le Bras et al in 1994. This study measured the MLR in 39 patients with vertebral or basilar artery strokes, which were documented via computed tomography scan or magnetic resonance imaging. Of these patients, 25/39 (0.64) showed unilateral or bilateral delay of the Pa wave of the MLR (5 unilateral and 20 bilateral). The sample was further divided by lesion type; $10 / 15(0.66)$ patients with insult to the pons showed MLR abnormalities, 2/7 (0.28) with mesencephalon insult showed MLR abnormalities, and the remaining patients with MLR abnormalities had more diffuse brain stem lesions (Henry-Le Bras et al, 1994). Another smaller study examined nine patients with quadrageminal plate tumors (Fischer et al, 1994). Eight of these patients showed abnormal MLR findings; 5/8 (0.62) showed both abnormal ABRs and MLRs, and 3/8 (0.37) showed abnormal MLRs in the presence of normal ABRs. In most cases, the MLR components were present, but $\mathrm{Na}$ and/or $\mathrm{Pa}$ were delayed. Detailed imaging and site-of-lesion information were described for each patient. In contrast, another study indicated that in seven patients with localized brain stem or thalamic lesions, only two patients showed abnormal MLR results $(2 / 7,0.28)$ in the form of delayed Na latencies and both were patients with thalamic lesions (Kaseda et al, 1991).

Multiple case studies of MLR abnormalities with brain stem involvement have also been reported. One case study described a middle-aged patient with a small punctuate hematoma bilaterally in the inferior colliculi due to a skiing accident. The patient reported multiple symptoms of auditory agnosia, and MLR results revealed the absence of $\mathrm{Pa}$ over one hemisphere (Johkura et al, 1998). Similarly, another case was reported involving a 13-year-old girl with an iatrogenic lesion (after undergoing tumor removal) affecting the left inferior colliculus, brachium, and MGB. Presurgery MLRs were normal bilaterally; postsurgical results showed the absence of a response over the left hemisphere and asymmetry in the response over the right hemisphere by ear of stimulation (Fischer et al, 1995). A more recent case (Cho et al, 2005) indicated normal MLR responses bilaterally in the case of a small hemorrhagic cavernous angioma, despite the extinction of right ear responses on a dichotic listening test, as well as abnormal ABRs on one side.

\section{ABR Abnormalities}

Of the studies mentioned previously, only two reported ABR results in addition to the MLR. An important question then arises about the degree to which an abnormal ABR related to a brain stem lesion may influence the subsequent MLR morphology. Obviously, the type and degree of abnormality of the ABR plays a role. It is unlikely that an absent ABR or ABR with absent later waves will coexist with a normal MLR. However, 
ABRs with mild abnormalities such as minimal latency extensions could potentially yield a normally structured MLR. This is likely related to the fact that the time base for the synchronous impulses contributing to the ABR waves is much shorter than the MLR waves. This simply indicates that the MLR waves can be constructed from voltages less synchronous than those of the ABR waves (Squires and Hecox, 1983). Put another way, voltages for each $A B R$ wave must accumulate within a $1 \mathrm{msec}$ time period to contribute to individual waves, whereas the MLR could have voltages that contribute to the $\mathrm{Pa}$ wave ranging over a 10 - to 15 -msec time period.

The generators of the MLR receive input from the brain stem auditory structures. Therefore, various MLR indices will reflect, at least to some degree, the integrity of the brain stem pathways. The MLR is not as time/synchrony dependent as the ABR and hence may on occasion, be present and normal even if the ABR is compromised. Recording the ABR and MLR simultaneously would allow for more precise site-of-lesion determination for brain stem/midbrain lesions (Musiek et al, 1984). If the ABR is normal and the MLR is abnormal, this would be indicative of a problem in the thalamocortical pathway but not the brain stem (Musiek and Lee, 1999).

\section{Cortical Lesions}

Whereas several large-scale and case studies have examined the effect of brain stem lesions on the MLR, many more studies have investigated the effects of various types of cortical lesions. These studies include patients with neurodegenerative diseases, strokes, brain trauma, and other types of lesions and help provide more complete information about overall utility and sensitivity of the MLR to brain lesions of various types (see Figures 2A and B). These studies typically take the form of case studies or larger scale clinical studies that may or may not use a control group of neurologically normal individuals for comparison. Common indices used for dysfunction include statistically significant differences in latency or amplitude of any of the MLR components $(\mathrm{Na}, \mathrm{Pa}, \mathrm{Nb}$, or $\mathrm{Pb}$ ) between control and patient groups; increased latency of any MLR components compared with previously published normative data; substantial asymmetries in latency or amplitude between recording sites or stimulation ear within the same patient; or absence of any MLR components in a waveform.

\section{Neurodegenerative Disease}

\section{Alzheimer's Disease/Dementia-Alzheimer's Type}

Multiple studies have compared MLR results between patient groups with Alzheimer's disease and
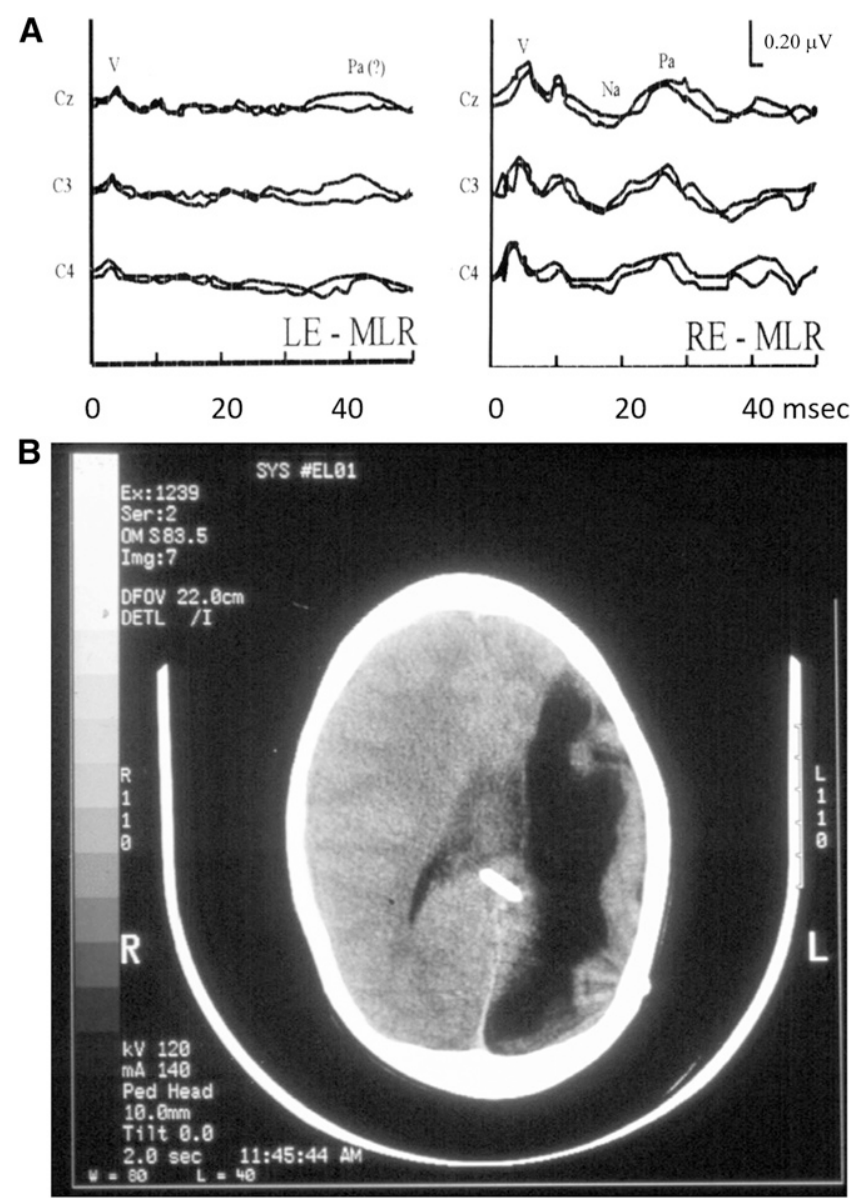

Figure 2. (A) The MLR of a ten-year-old, recorded at $\mathrm{Cz}, \mathrm{C} 3$, and $\mathrm{C} 4$ electrode sites using a $70-\mathrm{dB}$ nHL click stimulus. The repetition rate was 9.7 per second and filtering was $20-1500 \mathrm{~Hz}$. The left ear shows an attenuated wave $\mathrm{V}$ and essentially an absent MLR for all three recording sites, yielding an "ear effect." The right ear MLR shows that normal latency for $\mathrm{Na}$ and $\mathrm{Pa}$ waves is reduced in amplitude. (B) A computed tomography scan for figure (A) MLR, showing an arachnoid cyst in the left hemisphere.

neurologically normal controls, with varied and conflicting results. In one study of 14 patients with dementia-Alzheimer's type, mean Pa amplitude was found to be significantly larger in the patient group than in the control group (Phillips et al, 1997). In direct contrast, another study that assessed 35 patients with Alzheimer's disease found significantly reduced $\mathrm{Pa}$ amplitude in the patient group compared with the control group (Grimes et al, 1987). A third study that included 39 patients with Alzheimer's disease showed no significant differences in latency, amplitude, or wave presence between patient and control groups.

\section{Multiple Sclerosis}

In contrast to the divergent results described previously, MLR abnormalities in patients with multiple sclerosis seem to be more consistent and widespread. 
Several studies have shown various MLR abnormalities in close to $50 \%$ of the patients assessed with multiple sclerosis. Japaridze et al (2002) showed that $17 / 40$ (0.42) patients with suspected or definite multiple sclerosis showed abnormalities in the MLR waveform; these abnormalities were either increased latencies compared with control participants, or absent/undetectable waveform components. Similarly, Celebisoy et al (1996) described MLR abnormalities in 22/30 (0.73) patients with definite multiple sclerosis. Of those, 17 waveforms showed $\mathrm{Na}$ abnormalities (seven showed unilateral or bilateral increases in $\mathrm{Na}$ latency, ten showed unilateral or bilateral absence of the Na component). Additional abnormalities were present for the Pa component, with 16 waveforms showing $\mathrm{Pa}$ abnormalities of some kind (six showed unilateral or bilateral increases in $\mathrm{Pa}$ latency and ten showed unilateral or bilateral absence of $\mathrm{Pa}$ ). Some waveforms showed both $\mathrm{Na}$ and $\mathrm{Pa}$ abnormalities (Celebisoy et al, 1996). In addition, that same study showed significantly longer $\mathrm{Na}$ and $\mathrm{Pa}$ latencies for the multiple sclerosis group when compared with the control group. Similar $\mathrm{Na}$ and $\mathrm{Pa}$ differences were noted by Versino et al (1992) in their study of 34 individuals with definite or suspected multiple sclerosis. These authors showed 12 waveforms with $\mathrm{Na}$ differences (seven containing unilateral or bilateral increases in $\mathrm{Na}$ latency and five containing unilateral or bilateral absence of the Na component), and 11 waveforms with $\mathrm{Pa}$ differences (six containing increased $\mathrm{Pa}$ latencies unilaterally or bilaterally and five containing unilateral or bilateral absence of the $\mathrm{Pa}$ component). Overall, these authors found 16/34 (0.47) multiple sclerosis patients to exhibit abnormal MLRs (Versino et al, 1992).

Although other studies have not provided clear breakdowns by specific abnormality, overall results have been similar. Robinson and Rudge (1977) found MLR abnormalities including increased latency of $\mathrm{Pa}, \mathrm{Nb}$, or $\mathrm{Pb}$ components in 30/66 patients (0.45) with definite multiple sclerosis. One study by Hendler et al (1990) showed the smallest proportion of abnormalities in patients with definite multiple sclerosis; only $4 / 15(0.26)$ patients in that study showed abnormal MLRs, with unilateral or bilateral prolongation of Pa latency the only abnormality found. Finally, one case study reports an ear effect seen in a patient with multiple sclerosis, such that amplitudes at all electrodes for waveforms elicited by right ear stimulation were substantially smaller $(<50 \%)$ than in waveforms elicited by left ear stimulation (Schochat et al, 2006).

\section{Other Neurodegenerative Diseases}

MLR results have been varied for other types of neurodegenerative diseases. Specifically, one study that examined nine patients with Friedrich's ataxia found that 5/9 (0.55) patients showed MLR abnormalities, with unilateral or bilateral absence of $\mathrm{Na}$ (Amantini et al, 1984). In another study, 12 patients with cortical cerebellar atrophy were compared with 12 normal controls and no significant differences in amplitude or latency were found between groups.

Stroke: Several group studies have been performed on individuals with neurological lesions due to vascular issues within the brain (aneurysms, ischemic, and/or hemorrhagic strokes). One of the largest studies to date in this population was conducted by Kraus et al (1982). These researchers examined MLR recordings from 25 individuals with cortical lesions (11 left hemispheres, 4 right hemispheres, and 10 bilateral) due to middle cerebral artery strokes. All patients underwent recording from a vertex electrode site and a subset of nine patients underwent recordings at temporal electrode sites as well. Of the 25 patients, 12 showed abnormal $\mathrm{Pa}$ waves at the vertex recording sites. Abnormalities included late (four patients), reduced amplitude (four patients), or absent waveforms (four patients). Six of the nine patients who had waveforms recorded from temporal electrode sites showed asymmetrical amplitudes between electrode sites (the electrode effect) and four of the six had normal vertex recordings. So in total, 16/25 (0.64) patients tested exhibited MLR abnormalities of some kind.

Ibañez et al (1989) investigated 21 patients with unilateral strokes (9 left hemispheres and 12 right hemispheres) and compared their results with those from 16 controls with normal auditory and neurological function. These authors primarily focused on a within-subject amplitude asymmetry index (electrode effect) and normal absolute latency values derived from the normal control group as indications of dysfunction. Ultimately, 11/21 (0.52) patients showed MLR abnormalities, with all abnormalities manifesting as $\mathrm{Pa}$ amplitude asymmetries, such that amplitude was substantially decreased over the lesioned hemisphere. Interestingly, 10 of those 11 patients had suffered ischemic middle cerebral artery strokes affecting the auditory cortex or thalamocortical auditory radiations. Conversely, the ten patients with normal MLR waveforms had lesions limited to thalamic or capsule structures, with intact auditory cortical areas and auditory radiations (Ibañez et al, 1989).

More recently, Kaga et al (2004) assessed MLRs and middle latency auditory evoked fields in ten patients with unilateral temporoparietal strokes (nine left hemispheres and one right hemisphere) and compared their results with those from 15 normal controls. No statistically significant differences in latency or amplitude were found between groups, but a significant reduction in amplitude for right ear versus left ear stimulation (ear effect) was found for PaM, the middle latency auditory evoked field component analogous to $\mathrm{Pa}$ of the MLR, in the patient group (Kaga et al, 2004). Another 
longitudinal study also examined MLRs in ten patients with primarily left hemisphere strokes (Sosa et al, 2009). These authors, however, did not characterize MLR responses as normal/abnormal, nor did they compare results with normative data or a normal control group. Instead, Sosa et al (2009) examined and described changes in latencies from stroke onset until approximately six months poststroke. Patients generally had increased latencies poststroke that slowly returned to normal over time. Specifically, the latency of the $\mathrm{Nb}$ component of the MLR showed a significant and continuous reduction in latency across the group from stroke onset through six months poststroke.

In addition to the group studies described previously, numerous case studies have been published describing various stroke lesions and associated MLR abnormalities. Several studies have featured individuals with deep subcortical lesions (Godefroy et al, 1995; Baran et al, 2004; Hayashi and Hayashi, 2007). MLR waveforms obtained from these patients demonstrated an absent or difficult-to-detect Na component over the lesioned hemisphere (Hayashi and Hayashi, 2007), or a complete absence of the MLR waveform in all conditions, despite normal ABRs (Godefroy et al, 1995; Baran et al, 2004).

In six additional case studies, MLR results from patients with bilateral temporal lesions were described (Graham et al, 1980; Parving et al, 1980; Özdamar et al, 1982; Rosati et al, 1982; Ho et al, 1987; Musiek et al, 1994; 2007). In 5/6 (0.83) patients, MLR abnormalities were reported, including absent or difficult-todetect $\mathrm{Pa}$ waves over one or both hemispheres (Özdamar et al, 1982; Ho et al, 1987; Musiek et al, 2007); prolonged $\mathrm{Na}$ and Pa latencies (Rosati et al, 1982); and absence of all MLR components bilaterally (Graham et al, 1980). In the remaining patient, the MLR is described as occurring with all latencies within normal limits and no description of amplitude is provided. Musiek et al (1994) reported a case of right hemisphere stroke involving most of the cortical auditory regions. The findings reflected an electrode effect, which is a severely decreased amplitude from the electrode (T-4) placed over the lesioned area compared with the corresponding area over the noninvolved hemisphere (T-3).

Trauma: In addition to cerebrovascular accidents and strokes, traumatic head injury is another leading cause of cortical and subcortical lesions. In many studies, however, especially in cases of closed or minor head injuries, lesions may be more widespread and/or discrete lesions may not be identified; alternatively, head injury may be classified into degrees rather than by specific location. Munjal et al (2010) performed one very large study that used categorical classifications of head injury severity to describe MLR differences in 290 patients with closed head injury. Patients were divided into mild
(150 patients), moderate (100 patients), or severe (40 patients) head injury, and results from a control group of 50 participants with no head injury were obtained as well. Significantly lower $\mathrm{Pa}$ amplitudes were found overall in the head injury group compared with the control group, and significant differences in $\mathrm{Na}$ amplitude, $\mathrm{Pa}$ latency, and $\mathrm{Pa}$ amplitude between the different head injury groups (mild/moderate/severe). Ultimately, decreased Pa amplitude was the most common abnormality seen in the head injury group with roughly 33/ 290 (0.11) patients with head injuries showing abnormal $\mathrm{Pa}$ waves with right ear stimulation and 52/290 (0.17) patients showing abnormal $\mathrm{Pa}$ amplitude with left ear stimulation (Munjal et al, 2010).

Another large study examined 40 patients with minor head injuries and loss of consciousness and compared their MLR results with those obtained from 23 control participants with no history of head injury (Soustiel et al, 1995). These authors found significantly longer $\mathrm{Na}$ and $\mathrm{Pa}$ latencies in the patient group and noted that $15 / 40$ (0.37) patients showed MLRs with delayed MLR latencies. Interestingly, the delayed latencies in the patient group largely returned to normal when most of the patients were tested again three months after the initial head injury (Soustiel et al, 1995). Similarly, Drake et al (1996) found significantly longer Pa latencies in their 20 patients when compared with their control group. These authors also found significantly lower $\mathrm{Na}-\mathrm{Pa}$ amplitudes in their patient group as well (Drake et al, 1996).

In addition to the delayed latencies and decreased amplitudes noted in the previously mentioned studies, Ottaviani et al (1986) described absent $\mathrm{Pa}$ components in 12 out of $22(0.54)$ patients with head injury. Hall et al (1983) also found absent components, in addition to poor morphology and prolonged latencies in 3/3 participants with acute head injuries. Like Soustiel et al (1995), these authors noted some degree of improvement in MLR waveforms roughly two to ten months after the initial injury (Hall et al, 1983). This trend of initial dysfunction in the MLR waveform, followed by subsequent improvement may help to explain some seemingly discrepant results reported by Gaetz et al (2000). Gaetz et al (2000) found all $\mathrm{Na}$ and Pa latencies and amplitudes to be within normal limits and similar between 20 patients with postconcussive syndrome and 43 normal controls; however, $\geq 20$ months and as many as 59 months had elapsed between initial head injury and measurement of the MLR response.

\section{ABR Abnormalities}

Multiple studies that examined patients with head injuries and performed both the ABR and MLR noted that MLR had equal or greater sensitivity to these injuries than the ABR did (Soustiel et al, 1995; Munjal 
et al, 2010). Of course, overall sensitivity and specificity are optimized when the ABR and MLR are used in combination or recorded simultaneously.

\section{Other Lesion Types}

Several other studies have shown MLR differences in various populations. Gopal (2008) obtained MLRs from seven patients with solvent exposure and found that $1 / 7$ (0.14) patients showed an abnormal MLR, with poor morphology and poor replicability. Musiek et al (2004) published a case study of a patient with a subarachnoid bleed secondary to meningitis and found the MLR to be absent approximately one month after the bleed. Ultimately, the Pa component of the MLR began to form at a normal latency, but the $\mathrm{Na}$ component remained of low amplitude and difficult to detect (Musiek et al, 2004).

Epilepsy/Seizure Disorders: One study has examined the effects of epilepsy/seizure disorders on the MLR. Azumi et al (1993) recorded MLRs from 55 patients with epilepsy and compared them with those recorded from 55 normal controls. Results showed significantly delayed $\mathrm{Pa}$ and $\mathrm{Nb}$ latencies in the patient group and also showed that patients with recent seizures had significantly larger $\mathrm{Pa}-\mathrm{Nb}$ amplitudes compared with patients with well-controlled epilepsy and control (nonepileptic) participants (Azumi et al, 1993).

Tumors: Harker and Backoff (1980) examined MLR waveforms in 41 patients with various types of tumors (vestibular schwannomas, lipomas, and meningiomas) as well as a normal hearing control group, and a control group with sensorineural hearing loss due to a nontumor etiology. Waveform analysis showed significantly longer $\mathrm{Na}$ and $\mathrm{Pa}$ latencies in the tumor group compared with both control groups. In addition, within the tumor group, ten patients had latencies within normal limits, 30 patients showed abnormal latencies of at least one component, and one patient had an absent MLR (overall sensitivity $=31 / 41 ; 0.76$ ) (Harker and Backoff, 1980).

\section{Combined Studies-Multiple Lesion Types}

Whereas each of the studies described previously details MLR results for a specific lesion type or etiology, many other studies combine results from multiple lesion types or groups. Within these combination studies, details may or may not be available about specific lesions and their correlations with various MLR abnormalities.

The largest of these combined studies assessed 45 patients with neurological disorders and 16 neurologically normal controls (Kaseda et al, 1991). The patients were divided into two groups: Group A (25 patients) had nonlocalized lesions due to neurodegenerative diseases or other pathologies and Group B (20 patients) had localized lesions due to strokes or tumors. Two individuals in Group A, one with multiple sclerosis and one with spastic spinal paralysis, demonstrated abnormal MLRs with delayed Na latencies. In Group B, eight patients had abnormal waveforms. Four of these patients had unilateral thalamic or subcortical lesions and demonstrated $\mathrm{Na}$ abnormalities-increased latency or decreased amplitude for the ear contralateral to the lesion. The remaining four patients had cortical or subcortical lesions of the temporal lobe and showed $\mathrm{Pa}$ abnormalitiesdecreased $\mathrm{Pa}$ amplitude or absent Pa Ultimately, 10 out of 45 patients showed MLR abnormalities (0.22) (Kaseda et al, 1991). Woods and Clayworth (1985) reported on nine patients with unilateral cortical lesions with six showing electrode and/or ear effects; these authors also reported MLR abnormalities (ear and/or electrode effects) in $9 / 9$ patients with subcortical (thalamus or internal capsule) lesions.

Musiek et al (1999) administered the MLR to patients with a variety of lesions of the CANS. This was another rather large study with 26 control participants and 26 patients with CANS lesions. The most sensitive and specific index from that study was the "contralateral effect"; comparison of the amplitude obtained from the electrode contralateral to the lesion on stimulation of the opposite ear (i.e., comparison of the $\mathrm{C} 3$ amplitude obtained with right ear stimulation to the $\mathrm{C} 4$ amplitude obtained with left ear stimulation). Sensitivity and specificity rates for that index were approximately $73 \%$ and $83 \%$, respectively. This study also showed that latency measures of the MLR for individuals with cortical involvement were not as sensitive as the amplitude measures. Kileny et al (1987) also analyzed MLR results within various patient groups and in comparison to normal controls. These authors divided 16 patients with neurological disorders into groups of (a) 11 patients with unilateral temporal lobe lesions (due to stroke in most cases) and (b) 5 patients with unilateral frontal or parietal lesions. They also compared results with two patients with anterior temporal lobectomies and five neurologically normal control participants. Across groups, significantly lower $\mathrm{Na}-\mathrm{Pa}$ amplitudes were found in the temporal lobe group compared with the remainder of the patients and control participants. Within the temporal lobe group, both $\mathrm{Na}-\mathrm{Pa}$ amplitude and absolute $\mathrm{Pa}$ amplitude were significantly lower when recorded over the lesioned hemisphere when compared with the nonlesioned hemisphere (electrode effect).

Shehata-Dieler et al (1991) recorded MLRs from 19 patients with unilateral temporal lobe lesions and then further subdivided those patients into two groups: Group A consisted of 11 patients with lesions due to tumors, stroke, or trauma that included the auditory areas of the temporal lobe; Group B consisted of eight patients with lesions due to epilepsy, tumor, or trauma 
that affected only nonauditory parts of the temporal lobe. MLRs were also obtained from 30 neurologically intact control participants as well. Results analyzed across both patient groups (A and B) showed no significant amplitude differences between recordings from the ear ipsilateral to the lesion compared with the ear contralateral to the lesion, nor from recordings obtained over the lesioned hemisphere versus the nonlesioned hemisphere. In contrast, when Group A was analyzed more specifically, significantly lower $\mathrm{Na}-\mathrm{Pa}$ amplitudes and longer $\mathrm{Pa}$ latencies were found when compared with the normal control group, especially over the lesioned hemisphere. Within Group A, Na-Pa amplitude was significantly reduced over the lesioned hemisphere compared with the noninjured hemisphere (electrode effect) (Shehata-Dieler et al, 1991).

More recently, Pialarissi et al (2007) compared MLR results obtained from 20 patients with varied neurological disorders (tumors, neurodegenerative disease, psychiatric dysfunction, and stroke) to previously obtained MLR data from neurologically normal individuals. When results were compared between the neurological group and the normative data, the neurological group showed significant delays in $\mathrm{Na}, \mathrm{Pa}, \mathrm{Nb}$, and $\mathrm{Pb}$ latencies. Within the neurological group, no differences were found by ear site or electrode site; however, these authors only compared left and right sides and did not analyze results by ear or electrode site ipsilateral/ contralateral to the lesion (Pialarissi et al, 2007).

Finally, several smaller studies have also reported MLR abnormalities. Musiek and Lee (1997) compared results from ten patients with neurological dysfunction due to epilepsy or cerebrovascular issues with results from ten age- and hearing-matched controls. They found significantly reduced $\mathrm{Na}-\mathrm{Pa}$ amplitude in the patients recorded from the $\mathrm{C} 3$ electrode site with left ear stimulation and reduced $\mathrm{Pa}-\mathrm{Nb}$ amplitude for stimulation from either ear (Musiek and Lee, 1997). In contrast to most of the other studies described previously, the next study did not use a control group, and is more of a case report format (Woods et al, 1987). This study reports on five patients with bilateral superior temporal plane lesions. Of the three patients with cerebrovascular lesions, two showed minor asymmetries between stimulation ears. The remaining two patients had lesions due to stroke and one demonstrated increased Na latency, absent $\mathrm{Pa}$, and ear asymmetries (3/5 overall-0.6) (Woods et al, 1987).

\section{SUMMARY}

$\mathrm{O}$ verall, the MLR was fairly sensitive to brain stem/ midbrain lesions. Sensitivity for group studies ranged from 0.29 to 0.89 , with an average sensitivity of 0.56 . Sensitivity was similar overall for neurodegenerative diseases; MLR sensitivity ranged from 0.21 to
0.73 , with an average sensitivity of 0.48 . Sensitivity was higher for stroke cases, with a range of about $0.52-0.64$. In cases of head injury, sensitivity was lower overall (range $=0.38-0.55$; average $=0.465$ ). In accordance with these values from specific lesion studies, in the studies that combined lesion types, overall sensitivity was roughly 0.50 .

Several caveats are worth mentioning related to these sensitivity values. First, in cases of multiple sclerosis especially, sensitivity values likely reflect the variability in nerves affected by the disease. In most cases of multiple sclerosis, it is unknown if the auditory system is involved and in some cases, it likely is not. Therefore, sensitivity measures as related here may not and likely do not reflect the true value of the MLR. However, somewhat surprisingly, MLR sensitivity in some multiple sclerosis studies is competitive or better than the ABR's sensitivity to multiple sclerosis (Japaridze et al, 2002), which makes a compelling argument for simultaneous recording of the ABR and MLR to achieve the best hit rates (see Japaridze et al, 2002). In addition, various studies used multiple parameters for abnormality, such as delayed latency for either $\mathrm{Na}$ or $\mathrm{Pa}$, ear or electrode effects, comparison to a control group, as well as absence of waveform components. The use of multiple indices for dysfunction increases hit rate and thereby sensitivity. The variety in indices used across studies makes it difficult to derive a clear overall sensitivity value for the MLR.

\section{CONCLUSIONS}

$T$ his review demonstrates the potential value of the MLR from the diagnostic perspective across lesion types, especially for lesions affecting the cortical and subcortical areas rostral to the brain stem. The use of multiple indices, including ear effects, electrode effects, and delayed latencies or reduced amplitudes, compared with neurologically normal data will increase sensitivity of the MLR. Using the MLR with other diagnostic procedures, especially the ABR, makes it most useful. There are situations such as cases of central deafness where MLR becomes one of the few audiological alternatives that can lead to the diagnosis of this disorder.

Ultimately, the MLR may not be a test for everyday audiological use, but it can play a valuable role in siteof-lesion testing, particularly in cases where imaging may not be used frequently (multiple sclerosis and closed or mild head injury). Sensitivity for the MLR is good, especially in cases of cortical lesions. It can be combined with the ABR to help in differentiating brain stem from thalamocortical involvement, and with proper electrode application, the MLR can provide laterality information as well. In addition, as some of the closed head injury studies noted previously, the MLR can be an effective tool to document recovery 
and plasticity after insult to the brain. As with all advanced electrophysiologic procedures, experience and in depth knowledge of the MLR should be acquired before serious utilization of the procedure with patients, whether it be in the research or clinical domain.

Acknowledgments. The authors would like to acknowledge the following people for their contribution to this article: Alyssa Everett for her help in reviewing and preparing the manuscript, Jeff Weihing for his assistance in reviewing the information, and Nicholas Reed for his assistance in reviewing and summarizing data.

\section{REFERENCES}

Amantini A, Rossi L, De Scisciolo G, Bindi A, Pagnini P, Zappoli R. (1984) Auditory evoked potentials (early, middle, late components) and audiological tests in Friedreich's ataxia. Electroencephalogr Clin Neurophysiol 58(1):37-47.

Azumi T, Nakashima K, Takahashi K. (1993) Auditory middle latency responses in patients with epilepsy. Electromyogr Clin Neurophysiol 34(3):185-191.

Baess P, Widmann A, Roye A, Schroger E, Jacobsen T. (2009) Attenuated human auditory middle latency response and evoked 40-Hz response to self-initiated sounds. Eur J Neurosci 29: 1514-1521.

Baran JA, Bothfeld RW, Musiek FE. (2004) Central auditory deficits associated with compromise of the primary auditory cortex. $J$ Am Acad Audiol 15(2):106-116.

Celebisoy N, Aydo I, Ekmekçi Ö, Akürekli Ö. (1996) Middle latency auditory evoked potentials (MLAEPs) in (MS). Acta Neurol Scand 93(5):318-321.

Cho T, Fischer C, Nighoghossian N, Hermier M, Sindou M, Mauguièr F. (2005) Auditory and electrophysiological patterns of a unilateral lesion of the lateral lemniscus. Audiol Neurootol 10(3):153-158.

Drake ME, Jr, Weate SJ, Newell SA. (1996) Auditory evoked potentials in postconcussive syndrome. Electromyogr Clin Neurophysiol 36(8):457-462.

Eisencraft T, Miranda MFD, Schochat E. (2006) Comparing middle latency response with and without music. Braz J Otorhinolaryngol 72(4):465-469.

Erwin R, Buchwald JS. (1986) Midlatency auditory 175 evoked responses: differential effects of sleep in the human. Electroencephalogr Clin Neurophysiol 65:383-392.

Fifer RC, Sierra-Irizarry B. (1988) Clinical applications of the auditory middle latency response. Otol Neurotol 9:47-56.

Fischer C, Bognar L, Turjman F, Lapras C. (1995) Auditory evoked potentials in a patient with a unilateral lesion of the inferior colliculus and medial geniculate body. Electroencephalogr Clin Neurophysiol 96:261-267.

Fischer C, Bognar L, Turjman F, Villanyi E, Lapras C. (1994) Auditory early- and middle-latency evoked potentials in patients with quadrigeminal plate tumors. Neurosurgery 35(1):45-51.

Gaetz M, Goodman D, Weinberg H. (2000) Electrophysiological evidence for the cumulative effects of concussion. Brain Inj 14(12): 1077-1088.
Godefroy O, Leys D, Furby A, De Reuck J, Daems C, Rondepierre P, Debachy B, Deleume JF, Desaulty A. (1995) Psychoacoustical deficits related to bilateral subcortical hemorrhages a case with apperceptive auditory agnosia. Cortex 31(1):149-159.

Gopal KV. (2008) Audiological findings in individuals exposed to organic solvents: case studies. Noise Health 10(40):74.

Graham J, Greenwood R, Lecky B. (1980) Cortical deafness: a case report and review of the literature. J Neurol Sci 48(1):35-49.

Grimes AM, Grady CL, Pikus A. (1987) Auditory evoked potentials in patients with dementia of the Alzheimer type. Ear Hear 8(3): $157-161$

Hall J. (2007) New Handbook of Auditory Evoked Responses. Boston, MA: Allyn \& Bacon.

Hall JW, III, Huangfu M, Gennarelli TA, Dolinskas CA, Olson K, Berry GA. (1983) Auditory evoked response impedance measures and diagnostic speech audiometry in severe head injury. Otolaryngol Head Neck Surg 91:50-60.

Harker LA, Backoff P. (1980) Middle latency electric auditory responses in patients with acoustic neuroma. Otolaryngol Head Neck Surg 89(1):131-136.

Hashimoto I. (1982) Auditory evoked potentials from the human midbrain: slow brain stem responses. Electroencephalogr Clin Neurophysiol 53:652-657.

Hayashi K, Hayashi R. (2007) Pure word deafness due to left subcortical lesion: neurophysiological studies of two patients. Clin Neurophysiol 118(4):863-868.

Hendler T, Squires NK, Emmerich DS. (1990) Psychophysical measures of central auditory dysfunction in multiple sclerosis: neurophysiological and neuroanatomical correlates. Ear Hear 11(6):403-416.

Henry-Le Bras F, Fischer C, Nighoghossian N, Salord F, Trouillas P, Mauguire F. (1994) Brainstem and middle-latency auditory evoked potentials in vertebrobasilar strokes. Neurophysiol Clin 24:399-412.

Hinman CL, Buchwald JS. (1983) Depth evoked potential and single unit correlates of vertex midlatency auditory evoked responses. Brain Res 264(1):57-67.

Ho KJ, Kileny P, Paccioretti D, McLean DR. (1987) Neurologic, audiologic, and electrophysiologic sequelae of bilateral temporal lobe lesions. Arch Neurol 44(9):982-987.

Ibañez V, Deiber MP, Fischer C. (1989) Middle latency auditory evoked potentials in cortical lesions: criteria of interhemispheric asymmetry. Arch Neurol 46(12):1325-1332.

Jacobson GP, Grayson AS. (1988) The normal scalp topography of the middle latency auditory evoked potential Pa component following monaural click stimulation. Brain Topogr 1: $29-36$.

Japaridze G, Shakarishvili R, Kevanishvili Z. (2002) Auditory brainstem, middle-latency, and slow cortical responses in multiple sclerosis. Acta Neurol Scand 106(1):47-53.

Jerger J, Chmiel R, Glaze D, Frost J. (1987) Rate and filter dependence of the middle latency response in infants. Audiology 26: $269-283$

Johkura K, Matsumoto S, Hasegawa O, Kuroiwa Y. (1998) Defective auditory recognition after small hemorrhage in the inferior colliculi. J Neurol Sci 161:91-96. 
Kaga K, Hink RF, Shinoda Y, Suzuki J. (1980) Evidence for a primary cortical origin of a middle latency auditory evoked potential in cats. Electroencephalogr Clin Neurophysiol 50:254-266.

Kaga K, Kurauchi T, Yumoto M, Uno A. (2004) Middle-latency auditory-evoked magnetic fields in patients with auditory cortex lesions. Acta Otolaryngol 124(4):376-380.

Kaseda Y, Tobimatsu S, Morioka T, Kato M. (1991) Auditory middlelatency responses in patients with localized and non-localized lesions of the central nervous system. J Neurol 238(8):427-432.

Kileny P, Paccioretti D, Wilson AF. (1987) Effects of cortical lesions on middle-latency auditory evoked responses (MLR). Electroencephalogr Clin Neurophysiol 66(2):108-120.

Knight RT, Brailowsky S. (1990) Auditory evoked potentials from the primary auditory cortex of the cat: topographic and pharmacological studies. Electroencephalogr Clin Neurophysiol 77:225-232.

Kraus N, McGee T, Littman T, Nicol T. (1992) Reticular formation influences on primary and non-primary auditory pathways as reflected by the middle latency response. Brain Res 587(2): 186-194.

Kraus N, Nicol T. (2009) Auditory evoked potentials. In: Binder MD, Hirokawa N, Windhorst U, eds. Encyclopedia of Neuroscience. Berlin, Germany: Springer, 214-218.

Kraus N, Özdamar Ö, Hier D, Stein L. (1982) Auditory middle latency responses (MLRs) in patients with cortical lesions. Electroencephalogr Clin Neurophysiol 54(3):275-287.

Kraus N, Smith DI, McGee T. (1988) Midline and temporal lobe MLRs in the guinea pig originate from different generator systems: a conceptual framework for new and existing data. Electroencephalogr Clin Neurophysiol 70:541-558.

Kuriki S, Nogai T, Hirata Y. (1995) Cortical sources of middle latency responses of auditory evoked magnetic field. Hear Res 92: 47-51.

Liegeois-Chauvel C, Musolino A, Badier JM, Marquis P, Chauvel P. (1994) Evoked potentials recorded from the auditory cortex in man: evaluation and topography of the middle latency components. Electroencephalogr Clin Neurophysiol 92:201-214.

Makela JP, Hamalainen M, Hari R, McEvoy L. (1994) Whole-head mapping of middle-latency auditory evoked magnetic fields. Electroencephalogr Clin Neurophysiol 92:414-421.

McFarland WH, Vivion MC, Goldstein R. (1977) Middle components of the AER to tone-pips in normal-hearing and hearingimpaired subjects. J Speech Hear Res 20:781-798.

McGee T, Kraus N, Comperatore C, Nicol T. (1991) Subcortical and cortical components of the MLR generating system. Brain Res 544(2):211-220.

McGee T, Kraus N, Littman T, Nicol T. (1992) Contributions of medial geniculate body subdivisions to the middle latency response. Hear Res 61:147-154.

Møller AR, Kern JK, Grannemann B. (2005) Are the non-classical auditory pathways involved in autism and PDD? Neurol Res 27(6): 625-629.

Møller AR, Møller MB, Yokota M. (1992) Some forms of tinnitus may involve the extralemniscal auditory pathway. Laryngoscope 102(10):1165-1171.

Munjal SK, Panda NK, Pathak A. (2010) Audiological deficits after closed head injury. J Trauma Acute Care Surg 68(1):13-18.
Musiek F. (1991) Auditory evoked responses in site-of-lesion assessment. In: Fintelmann EF, ed. Hearing Assessment. Austin, TX: Allyn \& Bacon, 407-411.

Musiek FE, Baran JA. (2007) The Auditory System: Anatomy, Physiology and Clinical Correlates. Boston, MA: Allyn \& Bacon.

Musiek FE, Baran J, Pinheiro M. (1994) Neuroaudiology Case Studies. San Diego, CA: Singular Publishing Group.

Musiek FE, Baran JA, Shinn JB, Guenette L, Zaidan E, Weihing J. (2007) Central deafness: an audiological case study. Int $J$ Audiol 46(8):433-441.

Musiek F, Charette L, Kelly T, Lee W, Musiek E. (1999) Hit and false positives rates for the middle latency evoked response in patients with central nervous system involvement. J Am Acad Audiol 10:124-132.

Musiek FE, Charette L, Morse D, Baran JA. (2004) Central deafness associated with a midbrain lesion. J Am Acad Audiol 15(2): $133-151$

Musiek FE, Geurkink NA, Weider DJ, Donnelly K. (1984) Past, present, and future applications of the auditory middle latency response. Laryngoscope 94(12):1545-1553.

Musiek F, Lee WW. (1997) Conventional and maximum length sequences middle latency response in patients with central nervous system lesions. J Am Acad Audiol 8:173-180.

Musiek F, Lee W. (1999) Auditory middle and late potentials. In: Musiek F, Rintelmann W, eds. Contemporary Perspectives on Hearing Assessment. Boston, MA: Allyn \& Bacon, 243-272.

Musiek F, Mohanan A, Wierzbinski E, Kilgore G, Hunter J, Marotto J. (2011) The non-classical pathway: too great to be ignored. Hear $J$ 64(10):6.

Nagle S, Musiek FE. (2009) Morphological changes in the middle latency response using maximum length sequence stimuli. $J A m$ Acad Audiol 20(8):492-502.

Nelson MD, Hall JW, Jacobson GP. (1997) Factors affecting the recordability of auditory evoked response (AER) component $\mathrm{Pb}$ (P1). J Am Acad Audiol 8:44-52.

Ottaviani F, Almadori G, Calderazzo AB, Frenguelli A, Paludetti G. (1986) Auditory brain-stem (ABss) and middle latency auditory responses (MLRs) in the prognosis of severely head-injured patients. Electroencephalogr Clin Neurophysiol 65(3):196-202.

Özdamar Ö, Kraus N. (1983) Auditory middle-latency responses in humans. Audiology 22(1):34-49.

Özdamar Ö, Kraus N, Curry F. (1982) Auditory brain stem and middle latency responses in a patient with cortical deafness. Electroencephalogr Clin Neurophysiol 53(2):224-230.

Parving A, Salomon G, Elberling C, Larsen B, Lassen NA. (1980) Middle components of the auditory evoked response in bilateral temporal lobe lesions: report on a patient with auditory agnosia. Scand Audiol 9(3):161-167.

Peronnet F, Michel F. (1977) The asymmetry of auditory evoked potentials in normal man and patients with brain lesions. In: Desmedt JE, ed. Auditory Evoked Potentials in Man: Psychopharmacology Correlates of EPs. Basel, Switzerland: Karger, 130-141.

Phillips NA, Connolly J, Charles Mate-Kole C, Gray J. (1997) Individual differences in auditory middle latency responses in elderly adults and patients with Alzheimer's disease. Int $J$ Psychophys 27(2):125-136 
Pialarissi PR, Almeida FS, Camanducaia LC, Jorge JJ, Jr. (2007) Middle-latency auditory responses in neurological diseases. Braz J Otorhinolaryngol 73(4):540-548.

Picton TW. (2011) Human Auditory Evoked Potentials. San Diego, CA: Plural Publishing, Inc.

Ponton CW, Don M, Eggermont JJ, Waring MD, Masuda A. (1996) Maturation of human cortical auditory function: differences between normal-hearing children and children with cochlear implants. Ear Hear 17(5):430-437.

Pratt H. (2007) Middle-latency response. In: Burkard RF, Don M, Eggermont JJ, eds. Auditory Evoked Potentials: Basic Principles and Clinical Application. Baltimore, MD: Lippincott Williams \& Williams, 463-481.

Robinson K, Rudge P. (1977) Abnormalities of the auditory evoked potentials in patients with multiple sclerosis. Brain 100:19-40.

Rosati G, De Bastiani P, Paolino E, Prosser S, Arslan E, Artioli M. (1982) Clinical and audiological findings in a case of auditory agnosia. J Neurol 227(1):21-27.

Scherg M, Von Cramon D. (1986) Evoked dipole source potentials of the human auditory cortex. Electroencephalogr Clin Neurophysiol 65:344-360.

Schochat E, Matas CG, Sanches SGG, Carvallo RM, Matas S. (2006) Central auditory evaluation in multiple sclerosis: case report. Arch Neuropsych 64(3B):872-876.

Seki H, Kimura I, Ohnuma A, Saso S, Kogure K. (1993) The auditory evoked middle-latency responses (MLRs): their normative variation and generators. Tohuku J Exp Med 170:157-167.

Shehata-Dieler W, Shimizu H, Soliman SM, Tusa RJ. (1991) Middle latency auditory evoked potentials in temporal lobe disorders. Ear Hear 12(6):377-388.

Sosa R, Fraire Martínez MI, Olvera Gómez JL, JáureguiRenaud K. (2009) Early auditory middle latency evoked potentials correlates with recovery from aphasia after stroke. Clin Neurophysiol 120(1):136-139.

Soustiel JF, Hafner H, Chistyakov AV, Barzilai A, Feinsod M. (1995) Trigeminal and auditory evoked responses in minor head injuries and post-concussion syndrome. Brain Inj 9(8): 805-813.

Squires K, Hecox K. (1983) Electrophysiological evaluation of higher level auditory processing. Semi Hear 4:415-432.

Suzuki T, Hirabayashi M, Kobayashi K. (1984) Effects of analog and digital filtering on auditory middle latency responses in adults and young children. Ann Otol Rhinol Laryngol 93(3):267-270.

Tucker D, Ruth R. (1996) Effects of age, signal level, and signal rate on the auditory middle latency response. J Am Acad Audiol $7(2): 83-91$.

Versino M, Bergamaschi R, Romani A, Banfi P, Callieco R, Citterio A, Gerosa E, Cosi V. (1992) Middle latency auditory evoked potentials improve the detection of abnormalities along auditory pathways in multiple sclerosis patients. Electroencephalogr Clin Neurophysiol 84(3):296-299.

Woods DL, Clayworth CC. (1985) Click spatial position influences middle latency auditory evoked potentials (MAEPs) in humans. Electroencephalogr Clin Neurophysiol 60(2):122-129.

Woods DL, Clayworth CC, Knight RT, Simpson GV, Naeser MA. (1987) Generators of middle-and long-latency auditory evoked potentials: implications from studies of patients with bitemporal lesions. Electroencephalogr Clin Neurophysiol 68(2):132-148.

Yoshiura T, Ueno S, Iramina K, Masuda K. (1995) Source localization of middle latency auditory evoked magnetic fields. Brain Res 703:139-144.

Yvert B, Crouzeiz A, Bertrand O, Seither-Preisler A, Pantev C. (2001) Multiple supratemporal sources of magnetic and electric auditory evoked middle latency components in humans. Cereb Cortex 11:411-423. 